\title{
Site suitability evaluation for ecotourism using GIS and AHP: A case study of Isfahan Townships, Iran
}

\author{
Omid Mobaraki ${ }^{a^{*}}$, Mahdi Abdollahzadeh ${ }^{\mathrm{b}}$ and Zahra Kamelifar ${ }^{\mathrm{c}}$
}

${ }^{a}$ Department of Geography and Urban Planning University of Maraghe, Iran

${ }^{b}$ M.A in Geography and tourism planning

${ }^{c}$ M.A in Geography and Urban Planning, University of Mohaghegh Ardabili, Iran

CHRON I C L E

\section{Article history:}

Received January 14, 2014

Accepted 10 June 2014

Available online

June 222014

Keywords:

Ecotourism

Geographic Information System (GIS)

Analytical Hierarchy Process

(AHP)

Isfahan Township \begin{abstract}
A B S T RACT
Ecotourism, as a multibillion dollars business, is an industry with high potentials for economic competition. One of the proper solutions for developing ecotourism is better identification of different regions where there is a tourism capacity and accurate planning for performing feasibility study of those regions in terms of attracting ecotourism as well as creating infrastructures in those regions. This paper evaluates capacities and power of tourism as well as nature tourism in Isfahan Township using Geographic Information System and Analytical Hierarchy Process. The present research is applied and research method is descriptiveanalytical. Meanwhile, to analyze data, Arc GIS is used. Findings indicate that regarding the map of ecotourism capacity of Isfahan townships, resulted from combining various climatologically, geological, hydrological, topological maps and access maps, the township is not homogeneous in terms of nature tourism and coastal parts of the township (regions around Zayand-e-Rood) have better condition than other parts and should be considered for tourism development planning.
\end{abstract}

\section{Introduction}

Tourism is considered as an engine for national development and ecotourism plays essential role because of limitations on nature tourism targets, which causes development with environment protection is the essence of sustainable development (Garrison, 1989). In ecotourism, three important criteria must be considered: Appeals should be nature oriented; Tourists' reciprocal relationship should be focused on learning and education; and Managers of those environments should take measures in line with ecological, socio-cultural and economical sustainability (Weaver \& Lawton, 2007). In fact, following life-oriented philosophy and emphasizing on extrinsic and essential values, ecotourism provides possible sustainability through protecting natural environments, benefiting local communities, reinforcing characteristics of subcultures, providing opportunities for learning and education, reinforcing employment and preventing immigration, requiring less consumption of *Corresponding author.

E-mail addresses: omidmobaraki@gmail.com (O. Mobaraki) 
nonrenewable resources, bringing together opportunities for local participations, biological education, that is, combining environment protection and development and cultural heritages properly (Shayan \& Parsaei, 2007). Ideally, ecotourism should satisfy different measures such as protecting biological and cultural diversity trough protection of biological environment and promoting sustainable use of biodiversity with the least effect on the environment (Ryngnga, 2008). In this regard, ecotourism evaluation is an important tool for sustainable development of tourism in a given region (CeballosLascurain, 1996). The necessity of a serious look to ecotourism, as a new phenomenon in machine life of the $21^{\text {st }}$ century, is deeply felt and it becomes more and more important. This is because most cities have faced many problems because of rising trend of technology and mechanization in communities and expansion of new inventions (Butler, 2002). Therefore, people travel to natural and virgin regions so that they could enjoy landscapes, wild animals and plants, etc. Those actions influence natural environment and resources a little and play essential role in protecting various species of plants and animals (Bunruamkaew \& Murayam, 2011). Perceived capacity of ecotourism is considered as an effective tool in sustainable development mainly because developing countries value economic development and protection solutions now in such a way that ecotourism not only has expanded in natural virgin regions in a widespread manner, but also it is accepted among rural regions. Iran is not an exception in this regard. However, it should be noted that only regions proper for ecotourism will be developed and one should make sure that indexes would be in line with basic characteristics of a given region's resources. The help of determining indexes created as concepts of sustainable ecotourism management in a set of principles and indexes (Prabhu et al, 1999) may judge this. Therefore, development of ecotourism for maximizing positive effects and minimizing negative effects on all tourism aspects requires proper management. Combination of analytical hierarchy process (AHP) and GIS integrates decision support method with powerful imagery and mapping abilities, allowing drawing map of land proportion usage. Therefore, the current research makes efforts to identify ecotourism potential destination in Isfahan Township using AHP and GIS because, having a beautiful and virgin natural environment, Isfahan has high potential in terms of nature tourism. It is able to appeal many tourists if proper attention is paid and appropriate investment is performed. In fact, to investigate nature tourism capacity in Isfahan Township using AHP and GIS, after determining the potential of tourism destinations of the Township, the present study aims at paving the way for tourism development based on nature tourism.

\section{Study Area}

Isfahan Township is among townships of Isfahan Province, located Central Iran. Isfahan is located in between 30 degrees and 35 minutes to 34 degrees and 30 minutes of latitude and 49 degrees and 37 minutes to Eastern 55 degrees and 29 minutes of geographical longitude from Greenwich meridian. Its area equals to $15852 \mathrm{~km}^{2}$ and consists of 6 counties, 13 cities and 19 rural districts. The Township is limited to Nain, Ardestan, Barkhar and Meimeh Townships from North, Yazd Province from East, Khomienishahr, Flavarjan, Mobarakeh, Shahreza from West and Fars Province from South. From Southwest, it is near to Zagros Mountains, but from Northeast, it is far from Markazi Mountains. Its elevation above sea level is $1571 \mathrm{~m}$. Fig. 1 and Fig. 2 show location of studied region in Iran and Isfahan Province.
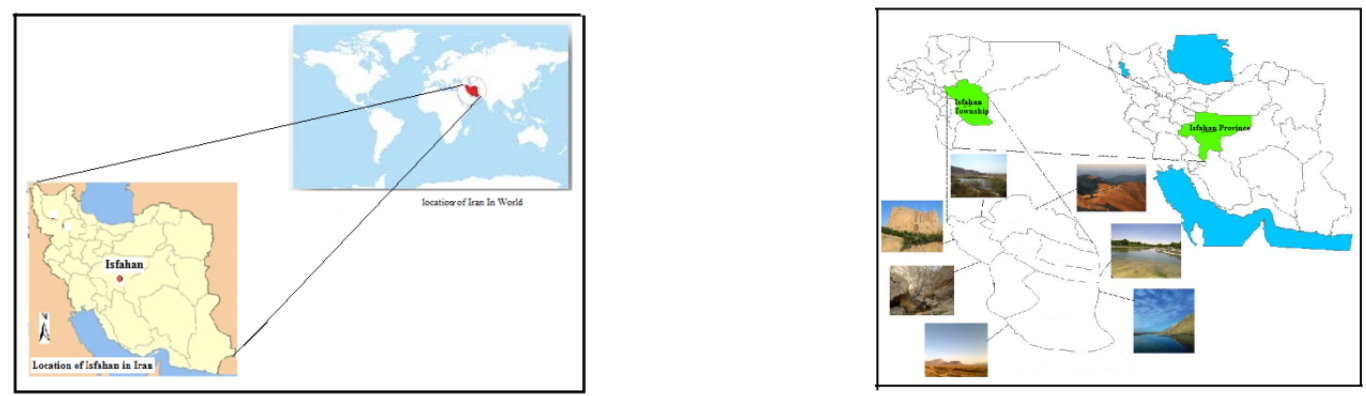

Fig. 1. Location of study area in Iran and world 


\section{Research Methodology}

Regarding research topic nature and goals, dominant research method is descriptive-analytical. Firstly, to evaluate ecotourism capacity of Isfahan Township, various climatologically, geological, hydrological, topological maps and access maps have been prepared. Then, using AHP extended in Arc GIS environment, the Township's ecotourism capacity has been evaluated. Used data in the current study has been collected from various resources. First, initial data for assessing ecotourism potential of the understudy region has been collected by field interview with specialists of tourism industry, consisting of important factors for positioning ecotourism in Isfahan Township. After specification of proper factors for evaluating land proportion for tourism development, data related to identified factors have been collected from different resources (including Iranian National Cartographic Center, Iranian Organization for Tourism and Cultural Heritage, Iranian Organization for Natural resources, Iranian various people and housing census, Iranian Transport and Roads Organization, Statistical center of Iran). All of mentioned data together with field data gathered from GPS and other data set form GIS needed data.

\subsection{Data collection}

In evaluating ecotourism potentials of different regions, it should be noted that investigated indexes have not the same weight for tourism activities. Therefore, there are various methods for giving weights to criteria or factors. In this regard, most important factors are ranking methods, rating methods, Pair Wise Comparison method (Farajzadeh, 2005). In the research presented here, to evaluate and decide better, AHP model has been used. Then, AHP levels, calculated by Expert Choice and Arc GIS, have been used in preparation of land proportion map. Four vital steps are taken for preparing land proportion map of Isfahan ecotourism include: (1) finding proper factors in order to be used in evaluation; (2) dedicating priorities to factors and rating involved factors; (3) drawing land proportion map for ecotourism; and (4) specifying regions having tourism capacity.

\section{AHP Model}

The analytic hierarchy process (AHP) (Saaty, 2008) is a structured technique for organizing and analyzing complex decisions, based on mathematics and psychology. AHP has particular application in group decision making, and is used around the world in a wide variety of decision situations, in fields such as government, business, industry, healthcare, tourism and education. Rather than prescribing a "correct" decision, the AHP helps decision makers find one that best suits their goal and their understanding of the problem. It provides a comprehensive and rational framework for structuring a decision problem, for representing and quantifying its elements, for relating those elements to overall goals, and for evaluating alternative solutions. Users of the AHP first decompose their decision problem into a hierarchy of more easily comprehended sub-problems, each of which can be analyzed independently. The elements of the hierarchy can relate to any aspect of the decision problem tangible or intangible, carefully measured or roughly estimated, well or poorly understood anything at all that applies to the decision at hand. Once the hierarchy is built, the decision makers systematically evaluate its various elements by comparing them to one another two at a time, with respect to their impact on an element above them in the hierarchy. In making the comparisons, the decision makers can use concrete data about the elements, but they typically use their judgments about the elements' relative meaning and importance. It is the essence of the AHP that human judgments, and not just the underlying information, can be used in performing the evaluations (Saaty, 2008). The AHP converts these evaluations to numerical values that can be processed and compared over the entire range of the problem. A numerical weight or priority is derived for each element of the hierarchy, allowing diverse and often incommensurable elements to be compared to one another in a rational and consistent way. This capability distinguishes the AHP from other decision making techniques. In the final step of the process, numerical priorities are calculated for each of the decision alternatives. AHP model have following steps: 
1. Define the problem and determine its goal. 2. Structure the hierarchy from the top (the objectives from a decision-makers viewpoint) through the intermediate levels (criteria on which subsequent levels depend) to the lowest level, which usually contains the list of alternatives. 3. Construct a set of pair-wise comparison matrices (size $n \times n$ ) for each of the lower levels with one matrix for each element in the level immediately above by using the relative scale measurement shown in Table 1. The pair-wise comparisons are done in terms of which element dominates the other. 4 . There are $\mathrm{n}(\mathrm{n}$ -1) / judgments required to develop the set of matrices in step 3. Reciprocals are automatically assigned in each pair-wise comparison. 5. Hierarchical synthesis is now used to weight the eigenvectors by the weights of the criteria and the sum is taken over all weighted eigenvector entries corresponding to those in the next lower level of the hierarchy. 6. Having made all the pair-wise comparisons, the consistency is determined by using the eigenvalue, $\lambda \max$, to calculate the consistency index, CI as follows: $\mathrm{CI}=(\lambda \max -\mathrm{n}) /(\mathrm{n}-1)$, where $\mathrm{n}$ is the matrix size. Judgment consistency can be checked by taking the consistency ratio (CR) of CI with the appropriate value in Table 2. The CR is acceptable, if it does not exceed 0.10. If it is more, the judgment matrix is inconsistent. To obtain a consistent matrix, judgments should be reviewed and improved. 7. Steps 3-6 are performed for all levels in the hierarchy(Goshal and et al, 2011).

Table 1

Pair-Wise Comparison Scale for AHP Preferences

\begin{tabular}{lclclc}
\hline Judgment & Rate & Judgment & Rate & Judgment & Rate \\
\hline Equally preferred & 1 & Moderately to strongly & 4 & Very strongly preferred & 7 \\
Equally to moderately & 2 & Strongly preferred & 5 & Very strongly to extremely & 8 \\
Moderately preferred & 3 & Strongly to very strongly & 6 & Extremely preferred & 9 \\
\hline
\end{tabular}

Table 2

Average Random Consistency (RI)

\begin{tabular}{lcccccccccc}
\hline Size of matrix & 1 & 2 & 3 & 4 & 5 & 6 & 7 & 8 & 9 & 10 \\
\hline Random Consistency & 0 & 0 & 0.58 & 0.9 & 1.12 & 1.24 & 1.32 & 1.41 & 1.45 & 1.49 \\
\hline
\end{tabular}

Fortunately, there is no need to implement the steps manually. Professional commercial software is available on the market which simplifies the implementation of the AHP's steps and automates many of its computations (AHP Calculation Software by CGI -web-based free software or Expert Choice, developed by Expert Choice, Inc.). In analytical hierarchy process, using AHP, after determining hierarchical levels including goal, criteria, sub criteria and options, pair comparison is done between sets for giving weights. While giving weights to sets, analysis of compatibility of judgments, which should be under 0.1 , is performed. Saaty put forth that if compatibility rate (CR) is under 0.1 , stability degree is well accepted. But, if it is above 0.1 , there is some instability in evaluation process and AHP may not have rational conclusions (Dey \& Ramcharan, 2008). In research procedure, ideas of specialists have been asked in order to calculate the importance assigned to factors and criteria involved. In addition, CR is calculated for each pair comparison in such manner that this value is 0.03 for pair comparison of criteria, which this amount is acceptable for land proportion analysis. Those calculations for matrix of pair comparison of criteria and CR are shown in following Tables 3 and 4.

Table 3

The priority OF Criteria's preference relative to each other

\begin{tabular}{|c|c|c|c|c|c|c|}
\hline Criteria & Access & Hydrology & Climate & Topology & Land cover & Geology \\
\hline Access & 1 & 3 & 5 & 7 & 9 & 5 \\
\hline Hydrology & 0.33 & 1 & 3 & 5 & 7 & 4 \\
\hline Climate & 0.2 & 0.33 & 1 & 3 & 5 & 5 \\
\hline Topology & 0.14 & 0.2 & 0.33 & 1 & 3 & 3 \\
\hline Land cover & 0.11 & 0.14 & 0.2 & 0.33 & 1 & 2 \\
\hline Geology & 0.2 & 0.25 & 0.2 & 0.33 & 0.5 & 1 \\
\hline Total & 1.98 & 4.92 & 9.73 & 16.66 & 25.5 & 20 \\
\hline
\end{tabular}


Table 4

Normalized of criteria preference

\begin{tabular}{ccccccccc}
\hline Criteria & Access & Hydrology & Climate & Topology & Land cover & Geology & Total & Weight \\
\hline Access & 0.5 & 0.609 & 0.513 & 0.42 & 0.352 & 0.25 & 2.64 & 0.44 \\
Hydrology & 0.166 & 0.203 & 0.308 & 0.3 & 0.274 & 0.2 & 1.45 & 0.241 \\
Climate & 0.101 & 0.069 & 0.102 & 0.18 & 0.196 & 0.25 & 0.896 & 0.149 \\
Topology & 0.07 & 0.04 & 0.033 & 0.06 & 0.11 & 0.15 & 0.47 & 0.078 \\
Land cover & 0.055 & 0.028 & 0.02 & 0.019 & 0.039 & 0.1 & 0.261 & 0.043 \\
Geology & 0.101 & 0.05 & 0.02 & 0.019 & 0.019 & 0.05 & 0.259 & 0.043 \\
\hline CI $=0.04, \mathrm{RI}=1.24, \mathrm{CR}=0.03$ & & & & & &
\end{tabular}

Table 5

Initial and final weight sub criteria

\begin{tabular}{|c|c|c|c|c|}
\hline Criteria & Weight & sub criteria & Primary score & Final score \\
\hline \multirow[b]{2}{*}{ Access } & \multirow{2}{*}{0.44} & Access to communication ways & 0.249 & 0.109 \\
\hline & & Access to urban settlement & 0.189 & 0.083 \\
\hline \multirow{2}{*}{ Hydrology } & \multirow{2}{*}{0.241} & Distance from waterways & 0.083 & 0.02 \\
\hline & & Waterways congestion & 0.063 & 0.015 \\
\hline \multirow{2}{*}{ Climate } & \multirow{2}{*}{0.149} & The rate of temperature & 0.048 & 0.007 \\
\hline & & Precipitation & 0.037 & 0.005 \\
\hline \multirow{3}{*}{ Topology } & \multirow{3}{*}{0.078} & Ground slope & 0.109 & 0.008 \\
\hline & & Slope direction & 0.015 & 0.001 \\
\hline & & Elevation & 0.143 & 0.011 \\
\hline \multirow{2}{*}{ Land cover } & \multirow{2}{*}{0.043} & Soil type & 0.02 & 0.0008 \\
\hline & & Vegetation & 0.027 & 0.001 \\
\hline Geology & 0.043 & Distance from fault & 0.0123 & 0.0005 \\
\hline
\end{tabular}

After categorizing and giving weights to data layers, considering the conditions of understudy region, overlapping of weighted maps are performed for each factor based on linear combination of proportion credit. Ultimately, land proportion map is achieved for ecotourism development in the region. Fig. 2 and Fig. 3 show evaluation model of the region's ecotourism capacity for tourism use in GIS environment.

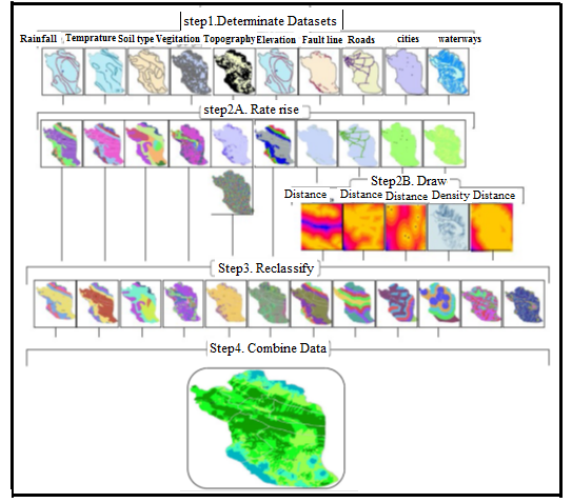

Fig. 2. Model of assessment for Isfahan township ecotourism potential for ecotourism application in GIS

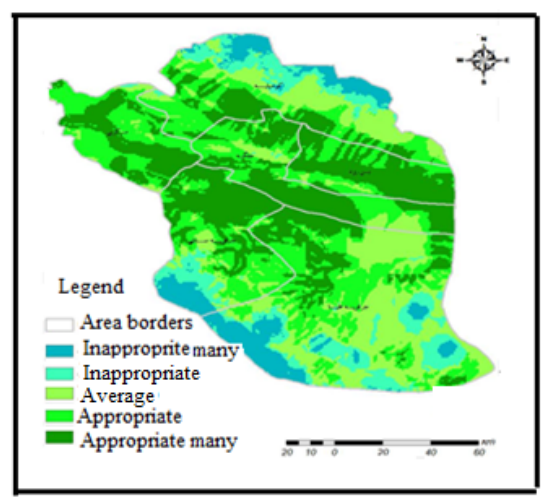

Fig. 3. Ecotourism potentials Isfahan Township

\section{Discussion and Conclusions}

As an equivalent form of tourism, in 1990s, ecotourism was introduced for correcting usual mistakes of tourism in satisfying needs of sustainable development (Leksakundilok, 2006). In addition, it has been proposed as one of the sustainable development solutions (Tsaur et al., 2006). Therefore, planning is urgently and basically needed for its progress and development. It should be designed based on all specific conditions of regions. Furthermore, while following International Tourism Organization standards, it should have solid executive background. One of the proper solutions for developing this section is better identifying different regions having nature tourism capacity. In addition, accurate planning is accomplished for feasibility study of those regions in terms of attraction of ecotourism and creation of infrastructures for those regions. The present research was a 
comprehensive method of ecotourism development through identification of tourism destinations and introduction of methods for investigating ecotourism with conforming characteristics of any given region with specifications considered best for ecotourism. This method helps decision making for planning tourism facilities and using ecotourism resources for sustainable development. In this process, various factors were effective including natural, environmental, human and service factors. Therefore, in the current study, GIS has been used; on the other hand, special credit was assigned to each layer and AHP has been used to specify those credits. Findings indicate that regarding ecotourism capacity, coastal parts of Isfahan (Zayand-e-Rood coastal parts) have more capacity than other parts. High incomes may be collected from those capacities through organized planning, widespread organization and true goals, equipment of facilities and resources and powerful and organized leadership. Through developing underdeveloped regions and employing local folks together with developing infrastructures, development of those regions is helped. To achieve those goals, we need to prepare nature tourism master plan by affiliated organizations to improve required facilities of the Township's tourism regions. We also need to build tourism facilities and services in regions capable of nature tourism. There is also a necessity to develop, to equip and to reinforce regions capable of nature tourism. We need to compile strategies for nature tourism promotion to create a framework for effective consistency among activities and investment of public and private sectors in development of nature tourism. We need to present criteria for constant inspection of nature tourism development and keeping it in a given sustainable capacities. We also need to pave the ways for developing human resources and institutionalizing the culture of sustainable use of nature tourism capacities. Finally, we need to monitor ecotourism regions to have a balance on natural events.

\section{References}

Bertolini, M., Braglia, M., \& Carmignani, G. (2006). Application of the AHP methodology in making a proposal for a public work contract. International Journal of Project Management, 24(5), 422-430.

Bunruamkaew, K., \& Murayam, Y. (2011). Site suitability evaluation for ecotourism using GIS \& AHP: A case study of Surat Thani province, Thailand. Procedia-Social and Behavioral Sciences, 21, 269-278.

Butler, R. W. (2000). Ecotourism-has it achieved maturity or has the bubble burst. Keynote address. Pacific Rim Tourism.

Ceballos-Lascurain, H. (1996). Tourism, ecotourism, and protected areas: The state of nature-based tourism around the world and guidelines for its development. Iucn.

Dey, P.K., \& Ramcharan, E. K. (2008). Analytic hierarchy process helps select site for limestone guarryexpalision in Barbados. Journal of Environmental Management.

Farajzadeh, M. (2005). Geography information system and application in tourism planning. Samt publication.

Garrison, L. (1989). Tourism Wave of the Fut We? World Development, UNDP.

Goshal, D. S. K., Naskar, S. K., \& Bose, D. D. (2012). AHP in Assessing Performance of Diploma InstitutesA Case Study. Journal of Technical Education and Training, 3(2), 69.

Leksakundilok, A. (2006). Community participation in ecotourism development in Thailand.

Prabhu, R., Colfer, C. J. P., \& Dudley, R. G. (1999). Guidelines for developing, testing and selecting criteria and indicators for sustainable forest management: a C\&I developer's reference (Vol. 1). CIFOR.

Ryngnga, P. K. (2008). Ecotourism prioritization: a geographic information system approach. South Asia Journal of Tourism \& heritage, 1(1), 49-56.

Saaty, T. L. (2008). Relative measurement and its generalization in decision making why pairwise comparisons are central in mathematics for the measurement of intangible factors the analytic hierarchy/network process. RACSAM-Revista de la Real Academia de Ciencias Exactas, Fisicas y Naturales. Serie A. Matematicas, 102(2), 251-318.

Shayan, S., \& Parsaei, E. (2007). Assessment of talented area of ecotourism development in Kohgiloeei and Boyerahmad. Journal of Tarbiyatmodarres, 154.

Tsaur, S. H., Lin, Y. C., \& Lin, J. H. (2006). Evaluating ecotourism sustainability from the integrated perspective of resource, community and tourism. Tourism management, 27(4), 640-653.

Weaver, D.B., \& Lawton, L.J. (2007). Twenty year son: The state of contemporary ecotourism research. Tourism Management, 28, 168. 